\title{
Empirically Supported Treatments: Implications for Training
}

\author{
Karen S. Calhoun \\ University of Georgia \\ Paul A. Pilkonis \\ University of Pittsburgh Medical School
}

\author{
Karla Moras \\ University of Pennsylvania \\ Lynn P. Rehm \\ University of Houston
}

\begin{abstract}
This article discusses the role of empirically supported treatments (ESTs) in the training of clinical psychologists. Training in ESTs can be integrated in ways that vary depending on the level of training and setting. Predoctoral programs, internships, postdoctoral programs, and continuing education are discussed in regard to special challenges and sequencing of training. A preliminary set of guidelines for training in ESTs is suggested.
\end{abstract}

The development of empirically supported treatment (EST) approaches, which have evolved out of the tradition of the Scientist-Practitioner Model (cf. Kendall \& Norton-Ford, 1982), presents major challenges for training in clinical psychology. How much of training should focus on ESTs? What level of knowledge of or competence in ESTs should be expected? How can practicing psychologists gain expertise in ESTs? The American Psychological Association (APA) Division 12 Task Force on Promotion and Dissemination of Psychological Procedures found that training in ESTs was somewhat limited both in doctoral programs and internships (Crits-Christoph, Frank, Chambless, Brody, \& Karp, 1995). However, ESTs have received considerable attention since the publication of the Task Force report (Task Force on Promotion and Dissemination of Psychological Procedures, 1995) and interest in training is increasing.

A positive impetus for training in EST skills is the current Guidelines and Principles for Accreditation of Programs in Professional Psychology (APA, 1996) and its mandate regarding sufficient attention to the empirical basis of psychological methods:

The relative emphasis a particular program places on science and practice should be consistent with its training objectives. However, all programs should enable their students to understand the value of science for the practice of psychology and the value of practice for the science of psychology, recognizing that the value of science for the practice of psychology requires attention to the empirical

Karen S. Calhoun, Psychology Department, University of Georgia; Karla Moras, Department of Psychiatry, University of Pennsylvania; Paul A. Pilkonis, Western Psychiatric Institute and Clinic, University of Pittsburgh Medical School; Lynn P. Rehm, Department of Psychology, University of Houston.

Preparation of this article was supported in part by National Institute of Mental Health Grant R21 MH52737. We thank Marsha D. Marcus for her contribution.

Correspondence concerning this article should be addressed to Karen S. Calhoun, Psychology Department, University of Georgia, Athens, Georgia 30602. Electronic mail may be sent to kcalhoun@uga.cc. uga.edu. basis for all methods involved in psychological practice [italics added]. (p. 3)

Along with the challenges ESTs represent for training, they carry advantages as well. The advent of ESTs presents clinical psychology with an unprecedented opportunity for facilitating the integration of science and practice in psychological therapy training. Clinical psychologists with training and expertise in ESTs are equipped to meet the demands for accountability and demonstrable results inherent in modern-day practice. With such training they are in a position to help develop treatment innovations as well as to help train and supervise nondoctoral providers as the need arises. An additional advantage of ESTs is their ability to facilitate training and enhance its reliability.

ESTs help to fill the gap left by the relative absence of research on which to base training recommendations (cf. Stein \& Lambert, 1995). Training programs of some type necessarily were used in the outcome studies that led to the identification of every EST. Thus, for all ESTs some information should be available on (a) the pretraining qualifications (e.g., amount and type of clinical training) of the therapists who efficaciously conducted the therapy in the studies that established it as an EST, (b) the procedures for training therapists used in the studies that were associated with efficacious outcomes, and (c) methods for systematically assessing a trainee's acquisition of the EST (i.e., therapist adherence measures). Some ESTs, such as interpersonal psychotherapy of depression (IPT; Klerman \& Weissman, 1993; Klerman, Weissman, Rounsaville, \& Chevron, 1984), are associated with extensive published information on training procedures and related materials (treatment manual, training videotape with illustrative vignettes, and therapy adherence measures). In general, the more recent the outcome research on an EST, the more likely that training materials and model training procedures are readily available. This is because of the increasing sophistication of research and researchers on issues associated with ESTs.

Training materials developed for efficacy studies of ESTs can facilitate several of the main goals of training in any form of psychological therapy, including (a) conceptual understanding of the theory of psychopathology and the related model of thera- 
peutic change underlying the therapy, (b) acquisition of specific intervention skills associated with an EST (including how and when to use them), (c) acquisition of general therapeutic skills that are intended to create a type of therapist-patient relationship and interaction pattern that will potentiate the therapeutic processes thought to be required for optimal efficacy of the EST, and (d) acquisition of skills needed to perform ongoing evaluations of the effectiveness of any therapy one might use (Moras, 1993). ESTs facilitate the fourth goal just mentioned because the published outcome studies for ESTs provide levels of symptom and other outcome criteria against which the progress of one's own patients can be evaluated.

Information needed to facilitate the first three of the foregoing training goals generally is contained in an EST's therapy manual and supporting materials such as videotapes that illustrate the conduct of specified interventions. However, the manuals and supporting materials for some ESTs are more adequate than others for training (Moras, 1993, discusses training-relevant features of manuals).

Ideally, recommendations for training in ESTs would be presented in the context of a comprehensive, empirically supported, chronologically phased training model. Such a model would include a sequence of training phases, tasks, and procedures, each of which was linked to (a) the standard sequence of training situations available to clinical doctoral students and (b) the main general goals of training in any psychotherapy (Moras, 1993). However, a comprehensive model is likely to have limited applied value now while the field still is struggling over the place of ESTs in APA-approved doctoral training programs. Without consensus on a sequence of phases for training in ESTs, the sequencing is now left to evolve as part of the current patchwork with little consistency or oversight.

A broad, general plan for sequencing training is reflected in the structure of this article. At the doctoral program level, training includes general skills common to all forms of treatment (e.g., forming a therapeutic relationship), knowledge of psychopathology and theoretical underpinnings of ESTs, basic-level skills in ESTs, and experience leading to basic competence in at least one EST. The internship teaches advanced skills in ESTs, application of ESTs to complex cases, and training to mastery in at least one EST. Postdoctoral training includes specialization and training to a high level of expertise in one or more ESTs, and in some cases, training in development and evaluation of ESTs. Continuing education must attempt the enormous task of providing introductory, as well as advanced, training in ESTs to professionals whose formal training preceded the advent of ESTs, and those who want to add new ESTs to their repertoire. Finally, in lieu of a comprehensive and empirically supported training model, we present a set of training method guidelines for ESTs. The guidelines can be adopted, in whole or in part, for EST training programs at any level, doctoral through continuing education.

\section{Predoctoral Training}

Doctoral programs have responsibility for giving students a sound academic background that includes a conceptual understanding of, and appreciation for, the interaction between science and practice: ESTs are examples of the product of this interac- tion. As ESTs evolve, they play an increasingly important role in training programs. This fact was recognized in the Guidelines and Principles for Accreditation of Programs in Professional Psychology (APA, 1996). Empirically supported intervention procedures are expected to be included as part of training, both academic (knowledge) and practical (competence). Specifically, the Guidelines list areas of "substantial understanding and competence" programs should provide. They include "formulating and implementing intervention strategies (including training in empirically supported procedures )" (p. 6). Additionally, programs should place students in practicum settings that "provide a wide range of training and educational experiences through applications of empirically supported intervention procedures" (p. 6). Therefore, even as debate continues about the value and limitations of ESTs, programs are expected to include some exposure to, and experience with, these forms of treatment. The survey conducted by the Task Force on Promotion and Dissemination of Psychological Procedures (Crits-Christoph et al., 1995) showed that coverage of specific ESTs by training programs was somewhat limited at that time. Of the 25 treatment approaches listed in the survey, didactic instruction was provided by clinical psychology programs in $46 \%$, on average. An average of $44 \%$ were taught in practicum. Although most programs offered some exposure to the treatments, $22 \%$ of programs offered didactic coverage of less than one-fourth of them. With subsequent changes in accreditation guidelines and the attention ESTs are receiving, programs must closely re-examine their approach to therapy training.

Doctoral programs bear the responsibility of setting the stage for the professional identity of students through the process of socialization that occurs in graduate school. The process includes informal interaction and modeling as well as didactic and experiential training. To facilitate the process, programs need faculty who are not only capable of teaching and supervising ESTs but who convey also an appropriate objectivity about them. In our experience, faculty attitudes toward ESTs, with regard to their strengths and limitations, are the primary factor determining whether, and how, they are taught.

Doctoral programs must balance many competing training demands, and fitting EST training into curricula can seem difficult. However, the length of training does not necessarily need to be extended. Incorporation of training in ESTs presents an opportunity to re-examine the content as well as the methods used in therapy training. In some sense, programs should be accountable for training outcomes just as practicing psychologists must be accountable for their work. The new accreditation guidelines (APA, 1996) ask programs to develop outcome measures appropriate to their mission and report the results.

In addition to streamlining curricula by de-emphasizing less essential and outdated elements, training in ESTs can, in our opinion, be more efficient than traditional approaches to therapy training. EST manuals are didactic tools that often summarize research on the procedures and give information relevant to goal-setting, limitations, outcome measures, dealing with complications, and so on. Supplemental training aids are often available, as well, such as workbooks and videotaped examples of procedures. Although ESTs are not available as yet for all problems, many common problems (e.g., anxiety, depression) and difficult-to-treat problems (e.g., borderline personality disorder) 
do have ESTs. Exposure to an EST's training materials can give students a conceptual understanding of the treatment, preparing them for practical experience that often comes later in their training. Training in one EST can facilitate learning of others because some share common elements and concepts. Transfer of training also can be seen in more general aspects of therapy such as goal-setting and fostering compliance.

Training in ESTs can be incorporated into a variety of settings and structures. They are extremely well suited to the vertical practicum team approach used at the University of Georgia and many other programs (Halgin \& Murphy, 1995). A faculty member supervises a small group of students who are at varying stages of training (from first year to postinternship). In addition to individual supervision, they meet regularly for case conferences and group supervision. Team members observe each other's cases (videotaping is often used), and students take on increasing responsibility and caseloads as they advance. The most advanced students assist in supervising the others and teach basic level skills (e.g., interviewing, relaxation training). Students usually remain with the same team for one academic year at a time. The use of ESTs within this structure facilitates instruction and might enhance the service provided in training settings. For example, team members can monitor adherence to the treatment manual and engage in problem solving when difficulties arise. Students are very enthusiastic about the vertical team system and especially like the opportunity to receive training in how to be a supervisor.

As the gatekeepers in control of entry into the profession, doctoral programs select future psychologists and introduce them into the profession. Ideally, more reliable selection criteria will be developed so that students are admitted who are well prepared to learn and use ESTs. This might mean more attention to the science of psychology in undergraduate curricula, and even, perhaps, better screening for potentially interfering problems of applicants. Halgin and Murphy (1995) noted that people who are interested in becoming therapists have more than the average number of personal problems and dysfunctional backgrounds. There is evidence that such backgrounds may even influence psychotherapists' choice of theoretical orientation (Rosin \& Knudson, 1986). Additional research on how therapist characteristics interact with treatment can inform selection and training decisions. A number of such characteristics have been suggested but research on them is limited, especially as they related to achieving competence in treatment approaches. Dobson and Shaw (1993) outlined six selection factors they considered critical in choosing trainees for cognitive therapy. These were (a) warmth, caring, empathy; (b) lack of personal psychopathology; (c) lack of personal issues such as hostility; (d) motivation to learn the treatment model and techniques; (e) ability to tolerate negative patient affective states; and (f) abstract conceptual ability. Some of these characteristics have received empirical support, notably warmth (e.g., Frank, Kupfer, Wagner, McEachran, \& Cornes, 1991). Training programs must address the question of how well they select for and/or train qualities shown to be important to treatment outcome.

The basic, general skills taught in graduate programs include the formation of a positive working relationship in therapy commonly referred to as a therapeutic alliance. The centrality of such an alliance for promoting positive outcomes continues to be the subject of much debate. There is disagreement on how important it is to include this alliance in training, and little guidance on the best methods to use for training. On the other hand, some research suggests that features of the patient-therapist interaction that are quantified by measures of the construct of therapeutic alliance contribute to outcome in several therapeutic modalities, including psychopharmacotherapy (Krupnick et al., 1996). Ilardi and Craighead (1994) reviewed the role of nonspecific treatment factors in cognitive-behavioral therapy for depression and concluded that both specific skills and nonspecific factors such as therapeutic alliance, are important. However, they suggested that other factors (i.e., presentation of the treatment rationale and assignment of homework tasks) appeared to be more important than the alliance itself in promoting the sense of hope and self-efficacy that seems to account for early treatment gains. More research is needed on nonspecific factors. It should be noted, however, that most treatment manuals, even those that do not focus specifically on alliance-building, assume that therapists have the skills to develop a cooperative working relationship.

Predoctoral programs should integrate EST training with a thorough knowledge of psychopathology and assessment-diagnosis, along with formulation of the individual case in the context of the psychopathological processes identified. Many ESTs are complex and require sophisticated judgments in their application to individual cases. Even ESTs that consist of relatively simple techniques can be misapplied. Therapists must be trained to evaluate the effectiveness of treatments and to change treatment strategies when necessary.

\section{Internship Training}

\section{Conceptual Understanding}

During internship, the "primary training method is experiential"' (APA, 1996, p. 12), and applicants are screened (in part) to ensure adequate didactic preparation. The assumption is that most of the necessary basic science background in both psychopathology and its treatment will have been provided in predoctoral graduate training. Efforts at improving conceptual understanding during internship should focus more on the interface between basic and applied science, or to use the current vocabulary, on applications of ESTs that address issues of effectiveness (e.g., clinical utility and extensions beyond the constraints of research protocols) and efficiency (e.g., cost-effectiveness).

Another effort to enhance conceptual understanding during internship should be aimed at the development of second-order inferences about treatment strategies. That is, clarification is needed of the "best practices" from families of ESTs, not only at the first-order level of brand-name treatments but also at the second-order level of psychological principles that underlie them, for example, the role of behavioral activation versus cognitive components in the treatment of depression (Jacobson et al., 1996) and the role of exposure in the treatment of anxiety disorders (Barlow \& Lehman, 1996). In addition, understanding of the classes of patients who are likely to benefit from specific ESTs is needed. Conventional categorical diagnosis using the Diagnostic and Statistical Manual of Mental Disorders (4th ed. [DSM-IV]; American Psychiatric Association, 1994) is one 
way of doing this, but given the questionable validity of some of the current categories (cf. Faraone. \& Tsuang, 1994; Zarin \& Earls, 1993) the present-day nomenclature should not be relied on exclusively. There are other (and potentially more valid) ways to identify and understand individual differences among patients that have important implications for treatment outcome (cf. the literature on personality and its relationship to psychopathology; Watson \& Clark, 1994). Understanding at other levels makes it possible to join with individual patients in a flexible way, without violating the principles underlying the intervention. Wilson (1996) emphasized this point in his characterization of how treatment protocols and manuals are best applied.

In addition, internships should offer some discussion of the evolution of manuals and treatment models toward second-generation, "strategic," theory-driven approaches in addition to first-generation approaches that rely more heavily on content (e.g., specific agendas for specific sessions) that trainees may absorb in too literal a way. Linehan's (1993) approach to the treatment of patients with borderline personality disorder, who present invariably with multiple, pressing problems, is an example of a second-generation strategy. She provided hierarchies of problems, sequential strategies for treating them, and a mix of specific tactics within strategies, and it is unlikely that the treatment of any two patients will be identical, although both treatments will be recognizable as dialectical behavior therapy.

There should also be some discussion of the pros and cons reflected in the current debates surrounding ESTs. There are many important arguments on their behalf. First, trainees must be helped to establish professional identity. It is necessary to develop a coherent identity and programmatic resources as a clinician and clinical scientist before one can play variations on that theme, and it is best to promote themes that are empirically supported. Second, by virtue of the shaping that occurs during treatment and manual development and during peer review throughout the grant application and publication process, ESTs are often better conceptualized, more clearly articulated, and more transparent than other approaches. The process enhances the empirical database that supports ESTs and makes them easier to teach and disseminate.

At the same time, arguments exist against an exclusive focus on ESTs. First, internship may be the final opportunity for generalist training. Therefore, the experience should involve exposure to a variety of techniques and conceptual frameworks that trainees are allowed to integrate on their own terms. (Such a position works best for students who are already committed to empiricism and sufficiently skeptical of what is currently knownperhaps more attention should be paid to who gets admitted to training programs on this basis.) Second, some room should be allowed for approaches or innovations less well supported by current data because they may provide potential new hypotheses for treatment development. The challenge is to produce a creative tension among those things currently accepted as state-of-theart, a recognition of their shortcomings, and novel efforts to operationalize new approaches in ways that are scientifically acceptable. The clinically significant effects of many treatments (especially when one looks beyond changes in acute symptoms and clinical status to functional impairment, performance in major social roles, and quality of life) are often modest (cf. Jacobson \& Truax, 1991; Tingey, Lambert, Burlingame, \& Han- sen, 1996), and generativity in developing new and better treatments needs to be encouraged.

On a different note relevant to internship training in medical settings, internships must encourage an understanding, from a systems perspective, of the functioning of interdisciplinary organizations, especially as this influences the pragmatics of treatment and its applications by psychologists. Interest and training in health psychology has burgeoned in the recent past, and it is important for trainees to have a full appreciation of the historical and contemporary roles of psychology, medicine, nursing, and other health-related professions in academic medical centers and other hospitals.

\section{Training in Specific EST Skills}

Several things can promote training in specific EST skills. In our experience, the most important is an internship infrastructure in which such treatments are already in place. One model is the specialty (often research) clinic that serves as the site for internship clinical placements. The availability of such clinics requires an institutional commitment and the presence of successful research investigators whose protocols create and sustain such programs. Unfortunately, in an era of constraint on federal research funding, access to such investigators is more often the exception than the rule.

Nonetheless, some opportunities remain. For example, at the Western Psychiatric Institute and Clinic (WPIC), a year-long commitment to introducing interns to IPT (Klerman et al., 1984) is possible because of the infrastructure developed during the course of several treatment outcome studies (e.g., Elkin et al., 1989; Frank et al., 1991). Training in IPT is provided as a twostage process. During Stage 1, didactic seminars and videotaped clinical material are presented over 8 to $10,90-\mathrm{min}$ sessions. Stage 2 is the individual treatment of a depressed patient judged suitable for IPT, with audiotaping of treatment sessions and weekly individual supervision. Patients are persons who were screened for inclusion in research protocols but then excluded for any of several reasons related to their clinical status (e.g., severity or duration of depression) or the feasibility of their research participation (e.g., lack of availability for long-term follow-up because of an anticipated change in residence.) They are then offered open treatment with IPT provided by a trainee. Outcomes may continue to be systematically assessed, but because trainees are not credentialed as research-quality therapists, their data are not included in research protocols.

ESTs that have an extended history of empirical support (e.g., some behavioral and cognitive-behavioral models) may be associated with greater opportunities for training outside the research specialty clinic. Some ESTS already have been incorporated into the milieu of different services on a routine basis. Examples include cognitive therapies for depression and anxiety disorders, exposure treatments for anxiety disorders, parent training programs in many treatment contexts for children, and psychoeducation programs for various disorders.

Internships may be able to provide conceptual exposure to many ESTs, but at the level of supervised experience, a more realistic goal is hands-on exposure to a small number, given the time limitations (usually one full-time year) for the internship. Such a goal also allows programs to "play to their strengths" - 
not to try to be all things to all people but rather to focus on those things at which they are best. Such strengths should be made clear to trainees during the recruitment process to enhance satisfying trainee-program matches.

A variety of potential obstacles can interfere with training in ESTs. In our experience, a major obstacle is the lack of faculty who are enthusiastic about ESTs, trained in them, and competent to provide supervision. Another ingredient is also essential: access to patients who are appropriate for the ESTs in which training is provided. Consensus is increasing that competence and "skill acquisition in psychotherapy derive more from the use of targeted goals, specific feedback, and guided practice than from simple exposure and unstructured supervision" (Beutler, 1995, p. 491; see also Luborsky, 1990). For optimal training, one needs an adequate supply of both patients and supervisors. Ideally, there should also be some commitment to evaluation and training in supervision itself if programs are to remain state of the art.

The constraints imposed by third-party payers, especially managed care programs, also deserve some comment in this context. Problems that arise regarding insurance coverages and payments are often not specific to ESTs but rather related to the general training status of predoctoral interns. In fact, it may be possible to make a stronger case on behalf of reimbursing the services of interns if one can point to empirical justification for their work. ESTs may be a useful tool for documenting the value of such services, especially when these treatments incorporate an explicit strategy for outcome evaluation.

\section{Training in General Treatment Skills}

Internship often provides exposure (perhaps for the first time) to patients with more severe forms of psychopathology; complicated, comorbid conditions; multiple social as well as psychological and interpersonal problems; and medical problems. Working with complex, "difficult" patients often helps to define the boundary conditions for applications of current ESTs, highlighting strengths and weaknesses and encouraging thinking about adaptations and innovations.

ESTs and their associated manuals are designed for prototypical patients, but with some early versions one common omission was instruction on strategies for patients who are refractory to treatment. Some general training is needed in coherent, theoretically relevant responses for vexing clinical problems: For example, patients who refuse to cooperate initially or who are slow to respond to first-line interventions, even if cooperative. In the former case, it may be necessary to consider empirically supported approaches to understanding and motivating patients who are reluctant to commit to the demands of ESTs (cf. Miller \& Rollnick, 1991; Prochaska, DiClemente, \& Norcross, 1992).

Hayes (1995) has identified such problems as a unique opportunity for doctoral level psychologists:

It seems likely that master's level therapists are the future primary mental health care service provider. Ph.D.s are needed to develop programs, evaluate programs, train, supervise, and to treat complicated cases that fail to be helped by standardized treatment protocols. . . . In complex, treatment resistant cases you have to adopt a kind of problem solving strategy - training in this kind of thinking

is what we are doing with science-based training. (p. 64)

Internship is an excellent time to enhance understanding of such clinical problems and to provide strategies for intervention as part of training in general treatment skills.

\section{Training in Treatment Evaluation Research}

One of the hallmarks of ESTs is their commitment to evaluation through research, and internship should be a time when that commitment is sustained as part of the training experience itself. The obvious prerequisite during internship, however, is an explicit effort to protect some time for research work. This goal may be most realistic at programs where support for the internship, financial and otherwise, is not tied exclusively to service provision. To cite one example within our personal experience, interns at WPIC are asked to select a research preceptor during the first month of the training year and to attempt to devote as much as $20 \%$ effort to research endeavors. This goal can not usually be achieved, however, by sheltering an entire day during the work week, given the demands of clinical practice, but it does set a benchmark for which to strive. Also, an institutional training grant for postdoctoral fellows is linked explicitly to the internship; the goal is to recruit some interns with an eye to a 3-year training sequence (1-year internship, 2year postdoctoral fellowship) as a way of encouraging academic, research-oriented careers.

To create an environment optimal for the future development of ESTs, there should be some explicit commitment not only to clinical research in general but also to the specific problems of therapist training and the acquisition of treatment skills: "More resources should be devoted to empirical investigations of the processes, methods, and outcomes of psychotherapy training" (Binder et al., 1993, p. 600).

\section{Postdoctoral Training}

\section{The Need}

Postdoctoral training in ESTs is a topic about which limited research evidence but considerable research experience can be brought to bear. ${ }^{1}$ The first question is the following: Is postdoctoral training needed for ESTs? A confident "yes" can be replied if goals of the profession of clinical psychology include (a) the development of practitioners who have expert-level competence in the conduct of ESTs and (b) increasing the number of clinical psychologists who can provide training-to-competence in ESTs.

What considerations indicate that postdoctoral training in ESTs is needed? One of the most compelling rationales is the current standard lengths of APA-approved clinical Ph.D and internship programs (e.g., 1-year internship), and the extensive educational requirements of both. The structure and requirements of graduate and internship programs make it highly unlikely that expert competence in the conduct of more than one

\footnotetext{
' Research experience has accumulated in part because the therapists in studies that led to the designation of ESTs often are at the postdoctoral level.
} 
EST can be attained without additional training time at the postdoctoral level. ${ }^{2}$ Postdoctoral training in ESTs also is justified by (a) the current marked variability of APA-approved clinical programs in the number of ESTs taught and adequacy of the training provided and (b) the fact that few APA-approved internships require interns to reach a criterion of competence in the conduct of any EST (Crits-Christoph et al., 1995). Moreover, the foregoing situation is likely to continue for some time, given the ongoing lack of consensus on the importance of including training in ESTs in clinical programs. Other reasons also justify postdoctoral training in ESTs and are discussed below.

1. No published evidence seems to exist on the amount of training (e.g., number of supervised cases) needed to develop expert competence in the various ESTs. However, many researchers who have experience training postdoctoral level therapists for studies of ESTs concur that substantially more training time and supervised training cases than they anticipated were required to achieve acceptable (i.e., not expert) levels of adherence and competence. Such observations strongly suggest that graduate and internship training, if kept at their current lengths and requirements, cannot provide the opportunity for students to achieve expert competence in most ESTs.

2. The ability to use and adapt ESTs effectively with nonprototypical patients (e.g., patients who have the disorder(s) for which an EST was developed plus other potentially complicating comorbid conditions) is most realistically acquired at the postdoctoral level, given both (a) the probable advantage of learning first to conduct an EST with patients who are prototypical for it and (b) the extensive standard requirements of graduate and internship programs.

3. Learning to competently conduct an EST is likely to proceed most rapidly when a trainee already has developed basic clinical skills (e.g., maintaining a supportive stance; the ability to monitor and repair a therapeutic alliance ). Stein and Lambert (1995) cited research that suggests that general clinical skills can be acquired in graduate and internship level clinical experiences.

4. Several ESTs already have been identified (Task Force, 1995; see also articles in This Special Section). Practitioners who want to learn more than one EST will not be able to obtain training-to-competence during graduate school and their internship in all ESTs in which they are interested. Moreover, some would argue that responsible practice now requires learning more than one EST unless a practitioner wants to maintain only a very limited, specialized practice.

5. Most states ( $\geq 38$ at present) require supervised clinical experience at the postdoctoral level to qualify to take the psychology licensing exam (Association of State and Provincial Psychology Boards, 1995). The requirement is at least partially based on the view that clinical experience during graduate school and internship is not typically sufficient to qualify one to practice independently. Postdoctoral training focused on ESTs is highly consistent with the competence aims of the requirement for postdoctoral supervised clinical experience.

6. Training in ESTs at the postdoctoral level can increase the number of clinical psychologists who are likely to qualify as supervisors in ESTs for graduate students and interns.

7. Postdoctoral training in ESTs has notable potential to both contribute to the refinement and further development of ESTs and to facilitate the conduct of needed studies of training methods. Postdoctoral trainees can be excellent informants for both purposes.

Crits-Christoph (1996), a member of the APA Division 12 Task Force on Promotion and Dissemination of Psychological Procedures, presented another perspective that supports postdoctoral training in ESTs. He concluded that the standard training options available to students (graduate, internship, postdoctoral) are more likely to facilitate widespread dissemination of ESTs than are retraining, continuing education opportunities for existing practitioners.

\section{Postdoctoral Training in ESTs: Options}

It is easier to justify postdoctoral training in ESTs than to provide firmly grounded recommendations on effective and efficient training methods. Most reviewers of the research literature on psychotherapy training conclude that the relevant research is surprisingly sparse (e.g., Stein \& Lambert, 1995). Educator-researchers with extensive experience teaching psychotherapy skills concur that empirical research is sorely needed on training methods (e.g., Binder et al., 1993). On the other hand, as noted earlier, ESTs provide a partial antidote to the lack of experimental findings on which to base training recommendations.

One excellent option. In the absence of an empirically based, comprehensive, phased training model, probably the most effective and efficient way now available to develop postdoctoral training programs in ESTs is for the developers of ESTs and/or those who conducted the studies that led to the identification of an EST to create programs. Such a process led to the establishment of one of the first, and still one of the few, postdoctoral training programs in an EST, that is, the cognitive therapy program at the Center for Cognitive Therapy at the University of Pennsylvania. Unfortunately, most researchers do not spontaneously opt to develop postdoctoral training programs in ESTs. Division 12 of the APA is in a position to promote such programs.

A second excellent option. Some U.S. internship settings are well-poised to offer postdoctoral training in ESTs (e.g., the internship program at WPIC in Pittsburgh). Integrating internships with postdoctoral training opportunities in ESTs would allow students who are interested in specific ESTs to select internships that would help them attain expert competence by means of postdoctoral training after the internship.

\section{Continuing Education}

\section{The Need}

Continuing education (CE) is perhaps the most problematic component of disseminating the ESTs. How does one get the

\footnotetext{
${ }^{2}$ The conviction of Karla Moras is that attaining expert-level competence in even one EST requires postdoctoral training given the current standard content and length of graduate and internship training programs in clinical psychology. The basis of this conviction is Karla Moras's own clinical training, which included unusually extensive supervised experience conducting psychological therapies, at both the graduate and internship levels; subsequent experiences learning ESTs, and then teaching graduate, postdoctoral students, and research protocol therapists two ESTs.
} 
knowledge and skill required for competent use of the ESTs to the field of current practitioners? Of the 69 references to the ESTs in the Spring 1996 issue of The Clinical Psychologist, 29 were published in the last 5 years and 52 in the last 10 years. The knowledge base regarding psychotherapy is changing rapidly, and keeping up with these changes is a challenge to practitioners in the field. Can the practitioner who received his or her degree 5 or 10 years ago keep up with the evidence and learn the new techniques with demonstrated efficacy? With a shortening half-life of professional knowledge, the idea that psychologists should be continuously involved in education throughout their careers becomes a more and more necessary professional assumption (cf. Dubin, 1972).

CE is now required for continued licensure in approximately 40 states. States vary considerably in the number of hours required. Kansas, for example, requires 100 hours every 2 years, whereas Texas requires 12 hours per year. The types of activities accepted also vary and may include formal university courses, courses or workshops approved by some recognized approval organization (e.g., APA, state psychological association, or the state licensing board itself), informal talks and colloquia, convention attendance, and home study. Many states identify categories of $\mathrm{CE}$ and require some minimum number of hours to be of the formally approved type. ESTs may of course be studied in many of these formats.

An added push for CE of ESTs comes from the changing health care system. Managed care systems and service under capitation require accountability. Mental health providers, like providers of all types in the new health system, will need to clearly identify the problems they are addressing, specify the treatment plan, and demonstrate effective outcomes. Pressures exist for targeted outcomes in relatively short time spans and cost-efficient delivery by the least expensive provider. Many ESTs meet these goals. They are targeted to change behaviors associated with specific disorders or problems; they are specifiable and specified in manuals; they have designated assessment methods and criteria to identify appropriate cases; many have associated assessment techniques for monitoring change; most are relatively short term; and many are operationalized for potential administration, under supervision, by nondoctoral clinicians.

\section{The Current Status}

The APA Division 12 Task Force on Promotion and Dissemination of Psychological Procedures (1995) surveyed training programs and internships. In general, they were not doing a very good job of teaching the ESTs. Less is known about the content of $\mathrm{CE}$ offerings, but one can guess that the situation in $\mathrm{CE}$ is no better than in the training programs. Training faculty might be expected to be more up to date on research findings than the average practitioner and more likely to incorporate new developments in their programs. The typical practitioner may be less aware of new developments in the research literature and they may be less likely to have time to seek out appropriate CE. A large proportion of $\mathrm{CE}$ offerings are initiated by $\mathrm{CE}$ vendors. For example, many convention workshops are offered on the basis of the workshop having been submitted by the potential vendor. Commercial workshops are offered around the country by for-profit or nonprofit organizations with a workshop package to sell. As such, the degree to which the ESTs are offered is to some extent a function of its originator's initiative to offer $\mathrm{CE}$ opportunities. Incentives are often minimal because presenters frequently are asked to adapt their presentations to different workshop formats. Also, opportunities may be sporadic as well as time consuming.

From another perspective, one of the positive aspects of ESTs for dissemination to the field is the fact that they are "manualized." The implication is that the procedure has been specified so that it can be accurately replicated and transferred to new settings. However, it is not the case that the manual is sufficient to learn the technique. In virtually all research studies that use manualized treatment, additional training is required of the therapists. To obtain treatment competence requires different levels of training for different forms of treatment. At one end of the continuum, cognitive therapy (CT) requires lengthy and extended training to obtain competence. For example, one of the most elaborate and sophisticated studies of the efficacy of psychotherapy was the National Institute of Mental Health Treatment of Depression Collaborative Research Program (Elkin et al., 1989). Therapists at three sites were trained in CT (Beck, Rush, Shaw, \& Emery, 1979) and in IPT. The adequacy of the competence of the CT therapists at the different sites was questioned (Jacobson \& Hollon, 1996). These experts questioned the adequacy of even the rather elaborate training and supervision system designed into this study. Surely they would not think that reading and following the manual would be sufficient for competent offering of CT.

The CT manuals (Beck, 1995; Beck et al., 1979), however, may be at one end of a spectrum of manuals. CT is a therapy system with a set of assumptions about the nature of psychopathology and an array of techniques that are guided by the central assumptions. Sophisticated clinical skills are involved in choosing the specific techniques to use in response to a specific problem presented by a patient at a given point in therapy. The manuals include a discussion of timing and of the typical errors made by novices with the approach. Other manuals describe more concrete and delimited procedures. Perhaps a procedure that is sufficiently operationalized could be learned adequately by an experienced clinician through self study. For example, Lewinsohn's behavioral program for depression is laid out as a course with lessons, exercises, workbooks, and homework assignments (Lewinsohn, Antonuccio, Steinmetz, \& Teri, 1984). The clinician may well be able to apply the program solely from the manual. For the most part, however, experience training therapists to conduct ESTs for studies indicates that some person-to-person training is necessary to acquire adequate competence on most of the ESTs.

The effectiveness of the training in workshops on ESTs also merits scrutiny. Little research is available on the effectiveness of $\mathrm{CE}$, especially in psychology. What research is available has largely been done on medical rather than psychological CE. Reviews by Davis, Thomson, Oxman, and Haynes (1992), and VandeCreek, Knapp, and Brace (1990) came to similar conclusions. They concluded that the usual workshop of a few hours does relatively little to change the behavior of the participants, and that more extended formats are necessary. According to VandeCreek et al. (1990), CE is effective if it (a) identifies a 
target audience, (b) the participants express a desire to learn, (c) the participants identify inadequacies in their current knowledge or skills, (d) the programs make the learning objectives clear, (e) the format requires active participation in discussion or clinical procedures or both, and (f) opportunity is provided for supervised practice beyond the period of training. These points make a good starting point for considering how to effectively disseminate ESTs.

\section{Improving CE Offerings}

Points (a), (b), and (c) above suggest that one of the requirements of a successful program of disseminating the ESTs is making practitioners more aware of their existence and motivating them to acquire the skills. Mandatory CE requirements may be one source of motivation, but they do not specifically motivate people to learn ESTs. One motivating function of the published list of ESTs may be to form a skill set that knowledgeable and up-to-date clinicians should aspire to acquire. A continuing series of brief articles describing ESTs in The Clinical Psychologist may also help to familiarize and motivate practitioners to learn ESTs.

There is a clear need in psychology for more systematic offerings of $\mathrm{CE}$ in more extended formats. Extended formats are needed, in part, so that participants can have time to have handson experience in the form of practice or role play with the new material. Multiple day courses, either massed or spaced over a period of weeks or weekends, like a full university course, are more appropriate formats for teaching and learning the ESTs. Follow-up after the primary training allows the participants to have had the opportunity to try the new procedure in their own practice. Follow-up is very important for assuring competent skill acquisition, for maintaining skills, and for increasing the likelihood of continued utilization of those skills. Opportunities for supervision or consultation on an individual basis or followup booster sessions should be part of effective CE offerings.

Assuring competent skill acquisition is another significant issue in CE. How does one know that the manual reader or the workshop participant has adequately acquired competence to apply one of the ESTs? Various organizations offer examinations for $\mathrm{CE}$ credit for home reading programs. For example, Guilford Publications offers APA-approved CE credits for passing exams based on reading selected titles from their catalog. APA itself offers home study credit based on examination for reading some of its publications and for studying videotaped presentations. Although these are commendable moves in the right direction, passing such a test is not a guarantee of competence in the procedure. Required brief quizzes at the end of APA workshops similarly only demonstrate that the participant has learned the major points. As noted in the final section of this article, some research evidence on training in ESTs (Chevron \& Rounsaville, 1983 ) indicates that performance on tests of mastery of didactic material is negatively correlated with performance of the therapy. There is a real need for better competency testing and for research on how to assess clinical competence, not just technical adherence, in the ESTs. The investigators who study ESTs are able to provide knowledge specifically on these questions.

\section{Some Positive Examples}

There are some positive examples of moves in the direction of making available to practicing psychologists more effective forms of CE for ESTs. The APA CE Committee has been exploring alternate venues for offering $C E$ such as video conferences and longer format offerings. Division 12 is experimenting with its Post Doctoral Institutes to try offering follow-up consultation. The Division 12 Task Force Report on Promotion and Dissemination of Psychological Procedures (1995) cites a model program in Atlanta offered by a private practice group, the Atlanta Center for Cognitive Therapy. In this program participants are certified as competent in CT only after extensive didactic and practical training, case consultation, and examination on case conceptualization and presentation. The program is also noteworthy for offering training in partnership with agencies and institutions to their clinicians, and in using alternative media such as phone consultation on videotaped therapy sessions. A number of universities and professional schools are beginning to offer similar training opportunities to practitioners, based in part on the model of the Center for Cognitive Therapy that Aaron Beck founded in Philadelphia.

Another positive example is the workshops being offered under the aegis of the Obsessive-Compulsive Foundation. This consumer group offers a training package to interested professional groups that includes a 3-day workshop in empirically supported exposure and response prevention techniques and then opportunities for participants to obtain follow-up phone consultation on cases.

Other vendors of CE, such as state psychological associations, public service agencies, private managed care companies, and commercial CE vendors, are entities that should be interested in the systematic offering of training in the ESTs. State associations offer CE as a service to their members. Managed care companies want effective and reasonable care to be available to their subscribers. A market may be opening to commercial vendors to offer ESTs. For example, The Psychological Corporation has plans to offer $C E$ in conjunction with books and clinical software on the ESTs. What is needed is for a group or groups of experts to be identifying new developments and setting agenda and curricula for systematic CE offerings. The APA CE Committee efforts and the Division 12 Task Force are a starting point for defining such a $\mathrm{CE}$ agenda for practicing psychologists.

\section{Pragmatic Interim Guidelines for Training in ESTs}

As noted earlier, the field is not yet at a point where recommendations for training in ESTs can be made in the context of a comprehensive, empirically supported training model that is linked to the standard stages of training in clinical psychology. However, a wealth of experience in training people to use ESTs has accumulated from research on them. Efficacy trials of ESTs and of other manualized psychological therapies (e.g., Strupp \& Binder, 1984) have yielded training-relevant observations and findings (e.g., Binder, 1993a, 1993b; Crits-Christoph et al., in press; Dobson \& Shaw, 1993; Foley, O'Malley, Rounsaville, Prusoff, \& Weissman, 1987; Henry, Schacht, Strupp, Butler, \& Binder, 1993; Henry, Strupp Butler, Schacht, \& Binder, 1993; Rounsaville, Chevron, Weissman, Prusoff, \& Frank, 1986) that 
can inform the development of nonresearch training programs in ESTs.

Seven training guidelines are presented here with the caveat that they are based on experience conducting EST training ${ }^{3}$ but lack support from systematic, controlled research. A few of the guidelines match those recommended by Levenson and Strupp (1996) based on their experience training thousands of experienced and novice therapists in psychodynamically oriented psychotherapy (e.g., Strupp \& Binder, 1984). The overlap, given the fact that the guidelines presented here emerged mainly from experience training therapists in two nonpsychodynamic ESTs suggests that the guidelines might have some generalizability to training in other ESTs. The guidelines also overlap somewhat with the five-part training sequence described by Dobson and Shaw (1993) based on their experience conducting training in cognitive therapy (Beck et al., 1979).

The guidelines are based on several assumptions, including (a) the trainees have limited prior didactic and experiential training in the EST they are learning, (b) the main goals of training in any form of psychological therapy include those listed earlier in this article (e.g., conceptual understanding, acquisition of specific intervention skills, etc), (c) the ultimate aim of training in an EST is to develop expert competence in it. Expert skill includes the ability to assess cases to determine the appropriateness of using the EST, apply the EST to difficult but apparently suitable cases, achieve outcomes similar to those associated with more prototypical cases, and supervise others in the EST, and (d) didactic material must be included in a training program for an EST to meet the aforementioned general goals of training in any psychological therapy.

\section{Guideline 1: Include Videotapes That Illustrate the Conduct of the Central Components of the EST in the Training Program}

Videotapes of prototypical conduct of an EST are probably the most efficiently effective elements of the initial phase of any training program, in terms of the amount of information conveyed per unit of training time and number of trainee questions answered about conducting the EST. Viewing tapes answers many questions that trainees do not know they have until they see in vivo implementation of the EST, as well as questions they spontaneously formulate during training sessions. Tapes also answer questions that even the most detail-oriented, conscientious trainer cannot anticipate. Given their efficiency communicating major amounts of information about how an EST is correctly implemented, videotapes should be used very early in a training program. It also is useful to review training tapes at least once after trainees have some experience conducting the EST.

Training videotapes for some ESTs were developed either for the studies that led to the designation of a therapy as an EST or subsequently. For example, at least one training videotape is available for IPT (Klerman et al., 1984). A set of training videotapes was made for the cognitive-behavioral panic control therapy examined in a recent multisite trial (Barlow \& Lehman, 1996).

\section{Guideline 2: Rely Mainly on Audio- or Videotapes of Therapy Sessions for Supervision, Rather Than on Trainees' Self-Reports}

Tapes of sessions are critically important components of training in most if not all ESTs. Tapes give supervisors the most accurate information possible on the correctness and completeness of a trainee's implementation of an EST. Tapes also are necessary because a basic requirement of ESTs is that therapists respond to patients' ongoing communications at the same time as the therapists implement the prescribed interventions.

The need for moment-to-moment responsiveness arises in part from the fact that ESTs, like all psychological therapies, are performed in the context of an interpersonal interaction. Therapeutic interactions inherently potentiate some type of ongoing dialogue between patient and therapist. Even ESTs that are based on highly specific intervention instructions must be adapted in unpredictable ways on a moment-to-moment basis as the therapist tries to maximize the fit between the interventions and conceptualizations of the EST and a patient's apparent "assumptive world," intellectual style, current state, and so on.

A related aspect of therapist responsiveness is that efficacious therapy requires a therapist to respond appropriately, both in content and affective tone, to a patient's spontaneous verbalizations and reactive statements while the therapist implements prescribed interventions. The skill with which a therapist responds to patients in the foregoing ways while she or he conducts an EST can only be observed by means of audio- or videotapes of therapy sessions.

The importance of using session tapes as the basis for supervision is supported by at least one empirical finding. Chevron and Rounsaville (1983) found that their own supervisory impressions of therapists whom they were training in IPT (Klerman et al., 1984) differed dramatically depending on the material on which their judgments were based. Specitically, their impressions of trainees' competence differed when based on videotapes of sessions versus the more traditional trainee self-report descriptions of the same sessions: Their ratings of trainees' performance based on videotapes versus trainee self-report were uncorrelated. At the same time, however, the interrater reliability of Chevron and Rounsaville's supervisory ratings of the same trainees based on review of videotapes of sessions was high (Pearson's $r=.88$ ). ${ }^{4}$ The latter finding suggests that the lack of correlation between supervisors' impressions of trainees' performance based on self-reported process notes versus videotapes

\footnotetext{
${ }^{3}$ The guidelines are based primarily on Karla Moras's experiences training in two ESTs: interpersonal psychotherapy of depression (Klerman \& Weissman, 1993; Klerman et al., 1984), and cognitive-behavioral therapy (CBT) for panic disorder (Craske \& Barlow, 1993). About half of the trainees were psychiatric residents; the others include postdoctoral individuals with clinical or social psychology backgrounds, and masters-level social workers. Some of the CBT training was done in the context of a multisite, randomized clinical trial (Barlow \& Lehman, 1996).

${ }^{4}$ A related finding of interest is that scores on a written multiplechoice exam that tested trainees' knowledge of IPT principles, etc., was negatively correlated with supervisors' ratings of trainees' skill performing IPT (Chevron \& Rounsaville, 1983).
} 
of sessions cannot be attributed to low reliability of the supervisors' ratings of trainees' performance.

The relative need for video versus audiotapes for supervision in an EST could depend on the proportion of interventions that are behavioral rather than verbal (e.g., demonstrations of symptom-inducing techniques in panic-control therapy), and that require the therapist to evaluate, use, and/or respond to nonverbal versus verbal features of a patient's participation in a therapy session.

\section{Guideline 3: Use Adherence Measures Developed for the EST to Systematically and Frequently Evaluate Each Trainee's Progress}

An important training material available for ESTs is observerrated therapist adherence measures. Such measures are developed to evaluate and record the extent to which therapists in the studies of ESTs implement the therapy as specified in the manual. (The quality and utility of adherence measures as adjuncts to training varies as a function of the resources and expertise that were allotted to developing the measure.)

Making adherence ratings generally will add little additional preparation time for supervisors if they base their supervision primarily on tapes of trainees' sessions as recommended here. Adherence ratings clearly identify any interventions that a trainee is omitting or failing to implement fully or correctly. Thus, a supervisor's adherence ratings provide information to individualize supervision sessions. Moreover, repeated ratings provide an ongoing index of change in a trainee's performance in targeted areas. Adherence ratings also can serve as an index of the final level of skill attained by each trainee.

\section{Guideline 4: Training Material That Illustrates Common Errors in the Implementation of Central Components of an EST Are Efficient Training Aids}

The training materials available for most ESTs do not yet include tapes or transcripts that illustrate incorrect implementation of central features of an EST. In the absence of existing materials of this type, supervisors can use observations from their training experiences to create them (e.g., videotapes of the supervisor role-playing common errors).

\section{Guideline 5: Group Supervision Using Audiotapes of Sessions Might Be More Efficient Than Individual Supervision in Terms of Rate of Learning}

The preceding statement identifies a fundamental empirical question on training methods. Group supervision based on tapes of sessions conducted by trainees who are members of the group seems to be an efficient supervision format in terms of amount of information conveyed per unit of supervisor time. Tapes of different trainees' sessions tend to illustrate different points about the conduct of the EST. Thus, group supervision that is focused on session tapes provided by each trainee can enable several trainees to receive instruction in several points simultaneously.

Unfortunately, group supervision can be differentially stressful for trainees who are markedly lower than other trainees in their initial aptitude for learning and performing an EST and/ or basic therapeutic skills (e.g., ability to be accurately responsive to a patient). The exposure of a trainee's aptitude to his or her peers seems to have the highest potential for iatrogenic effects (a) on trainees who have less initial aptitude, when (b) group supervision occurs in a particularly competitive broader educational context.

\section{Guideline 6: Expect to Provide Supervision on a Minimum of Three to Four Prototypical Cases for the EST, and a Minimum of Four More Nonprototypic Cases to Develop Minimally Adequate Skill Performing It}

Unfortunately, limited empirical evidence is available on the fundamental question of how many cases a trainee must receive supervision on to attain adequate skill to conduct an EST independently and efficaciously. The foregoing numbers are estimates based on (a) the experience of the authors who have had experience training in ESTs and (b) responses to an informal survey we did of investigators and supervisors who have worked on studies of ESTs.

Responses to the survey clearly indicated that estimating the number of training cases needed to attain minimum competence in various ESTs is not a straightforward task. Respondents were asked to "estimate the number of supervised training cases needed to develop adequate skill (adherence and competence) to conduct a therapy like panic control therapy (Craske \& Barlow, 1993) or IPT (Klerman et al., 1984) independently.' The respondents were told to assume that "the therapist in training has some experience conducting individual psychotherapy at the graduate school level (e.g., trainee therapist has treated at least 5-10 patients - not a complete neophyte-but has no training in the EST that she or he is to be taught." The estimates varied considerably. For example, M. Katherine Shear estimated a minimum of " 3 well-supervised cases" for panic control therapy (personal communication, May 13, 1997). Cory Newman estimated " 10 full-term (not dropout) cases for cognitive therapy" to achieve competence. He also estimated that 20 supervised cases were needed to attain the expert level of competence sometimes sought for studies of ESTs (personal communication, May 27, 1997). Another respondent observed that not all trainees meet the competence level desired for studies of ESTs and potential ESTs. The foregoing response echoes a point made by Dobson and Shaw (1993) based on their experience providing CT training.

\section{Guideline 7: Include Instruction in Ongoing Evaluation of a Patient's Response to the EST}

A valuable advantage of ESTs is that the published studies on them name the measures that were used to assess efficacy and give figures that indicate the amount of change on the measures that was associated with efficacy of the EST (i.e., for the duration of the treatments studied). Batteries of measures used in studies generally include one or more self-report patient measures that can readily be used by practitioners for ongoing evaluation of their therapies. Also, many study reports include scores on measures at intervals throughout the treatment. Interval 
scores can be used by practitioners to track the rate of progress of their own patients. Information of the foregoing type provides benchmark efficacy data that all practitioners can use to evaluate the absolute response and rate of response of patients to whom they are giving an EST.

\section{Conclusion}

This article is an initial step into a relatively new territorythe design, implementation, and dissemination of systematic and comprehensive training programs in ESTs for clinical psychology. Many of the views and recommendations are presented with the caveat that they have little or no supporting evidence from controlled research as yet. Rather, we drew on our own experiences and those of many colleagues as both recipients and providers of clinical skills training at all levels.

The history of research on psychological treatments includes some voices that called for major effort to be directed toward training in the conduct of the psychological therapies (e.g., Alberts \& Edelstein, 1990). Unfortunately, research initiatives comparable to those that have occurred on the development and testing of efficacious treatments are not evident. Moreover, much of the existing research on training has not received widespread attention or implementation. Perhaps the foregoing historical trends in clinical research reflect a spontaneous, "first things first' strategy, that is, a major initial focus on the development and identification of efficacious treatments. Now that some therapies that meet efficacy criteria have been identified and that also are articulated well enough to be disseminated widely, perhaps more research attention will go to the identification of efficacious and efficient training procedures.

A second limitation of this article is that important, relevant topics were omitted. For example, supervisor skills and qualities that promote efficacious and efficient training in ESTs and in other psychological therapies are not discussed. (See Matarazzo \& Patterson, 1986, for an excellent review of the topic.) Also, Henry, Schacht, et al. (1993) reported findings that suggest supervisory styles have differential efficacy in terms of promoting observable change in trainees' conduct of a manualized therapy. Recently, Holloway and Neufeldt (1995) reviewed the empirical literature on supervision as a training method for psychological therapies. One of the authors' conclusions is that no studies have compared the efficacy of supervision and other training methods. This is obviously a relevant research topic for the development of broad-based training in ESTs for clinical psychology.

Another important topic not discussed is potential misuse by managed care officials of training information on ESTs. For example, any estimates of the amount of training required to gain independent competence in the various ESTs should be well grounded. Underestimates of training time needed can fuel cost-based arguments that result in underqualified panels of providers. Caveats aside, we hope that this article potentiates recognition of and enthusiasm for the enormous research and knowledge-generating opportunities now available to clinical psychologists in the area of training in ESTs and other psychological therapies.

\section{References}

Alberts, G., \& Edelstein, B. (1990). Therapist training: A critical review of skill training studies. Clinical Psychology Review, 10, 497-511.

American Psychiatric Association. (1994). Diagnostic and statistical manual of mental disorders (4th ed.). Washington, DC: Author.

American Psychological Association. (1996). Guidelines and principles for accreditation of programs in professional psychology. Washington, DC: Author.

Association of State and Provincial Psychology Boards (1995). Handbook of licensing and certification requirements for psychologists in North America. Montgomery, AL: Author.

Barlow, D. H., \& Lehman, C. L. (1996). Advances in the psychosocial treatment of anxiety disorders: Implications for national health care. Archives of General Psychiatry, 53, 727-735.

Beck, A. T., Rush, A. J., Shaw, B. F., \& Emery, G. (1979). Cognitive therapy of depression. New York: Guilford.

Beck, J. (1995). Cognitive therapy: Basics and beyond. New York: Guilford Press.

Beutler, L. E. (1995). The germ theory myth and the myth of outcome homogeneity. Psychotherapy, 32, 489-494.

Binder, J. L. (1993a). Is it time to improve psychotherapy training? Clinical Psychology Review, 13, 301-319.

Binder, J. L. (1993b). Observations on the training of therapists in timelimited dynamic psychotherapy. Psychotherapy, 30, 592-598.

Binder, J. L., Strupp, H. H., Bongar, B., Lee, S. S., Messer, S., \& Peake, T. H. (1993). Recommendations for improving psychotherapy training based on experiences with manual-guided training and research: Epilogue. Psychotherapy, 30, 599-600.

Chevron, E., \& Rounsaville, B. J. (1983). Evaluating the clinical skills of psychotherapists: A comparison of techniques. Archives of General Psychiatry, 40, 1129-1132.

Craske, M. G., \& Barlow, D. H. (1993). Panic disorder and agoraphobia. In D. H. Barlow (Ed.), Clinical handbook of psychological disorders: A step-by-step treatment manual (2nd ed., pp. 1-47). New York: Guilford Press.

Crits-Christoph, P. (1996). The dissemination of efficacious psychological treatments. Clinical Psychology Science and Practice, 3, 260263.

Crits-Christoph, P., Frank, E., Chambless, D. L., Brody, C., \& Karp, J. F. (1995). Training in empirically validated treatments: What are clinical psychology students leaming? Professional Psychology: Research and Practice, 26, 514-522.

Crits-Christoph, P., Siqueland, L., Chiltams, J., Barber, J. P., Beck, A. T., Frank, A., Liese, B., Luborsky, L., Mark, D., Mercer, D., Onken, L. S., Najavits, L. M., Thase, M. E., \& Woody, G. (in press). Training in cognitive, supportive-expressive, and drug counseling therapies for cocaine dependence. Journal of Consulting and Clinical Psychology.

Davis, D. A., Thomson, M. A., Oxman, A. D., \& Haynes, R. B. (1992). Evidence for the effectiveness of CME: A review of randomized controlled trials. Journal of the American Medical Association, 268, 1111-1117.

Dobson, K. S., \& Shaw, B. F. (1993). The training of cognitive therapists: What have we learned from treatment manuals? Psychotherapy, 30, 573-575.

Dubin, S. S. (1972). Obsolescence or lifelong education: A choice for the profession. American Psychologist, 27, 486-498.

Elkin, I., Shea, M. T., Watkins, J. T., Imber, S. D., Sotsky, S. M., Collins, J. F., Glass, D. R., Pilkonis, P. A., Leber, W. R., Docherty, J. P., Fiester, S. J., \& Parloff, M. B. (1989). National Institute of Mental Health Treatment of Depression Collaborative Research Program: General effectiveness of treatments. Archives of General Psychiatry, 46, 971 982.

Faraone, S. V., \& Tsuang, M. (1994). Measuring diagnostic accuracy in 
the absence of a "gold standard." American Journal of Psychiatry, $151,650-657$.

Foley, S. H., O'Malley, S., Rounsaville, B., Prusoff, B. A., \& Weissman, M. M. (1987). The relationship of patient difficulty to therapist performance in interpersonal psychotherapy of depression. Journal of Affective Disorders, 12, 207-217.

Frank, E., Kupfer, D. J., Wagner, E. F., McEachran, A. B., \& Cornes, C. (1991). Efficacy of interpersonal psychotherapy as a maintenance treatment of recurrent depression. Archives of General Psychiatry, 48, 1053-1059.

Halgin, R. P., \& Murphy, R. A. (1995). Issues in the training of psychotherapists. In B. Bongar \& L. E. Beutler (Eds.), Comprehensive textbook of psychotherapy (pp. 434-455). New York: Oxford University Press.

Hayes, S. C. (1995). What do we want from scientific standards of psychological practice? In S. C. Hayes, V. M. Follette, R. M. Dawes, \& K. E. Grady (Eds.), Scientific standards of psychological practice: Issues and recommendations (pp. 49-66). Reno, NV: Context Press.

Henry, W. P., Schacht, T. E., Strupp, H. H., Butler, S. F., \& Binder, J. L. (1993). Effects of training in time-limited dynamic psychotherapy: Mediators of therapists responses to training. Journal of Consulting and Clinical Psychology, 61, 441-447.

Henry, W. P., Strupp, H. H., Butler, S. F., Schacht, T. E., \& Binder, J. L. (1993). Effects of training in time-limited psychotherapy: Changes in therapist behavior. Journal of Consulting and Clinical Psychology, $61,434-440$.

Holloway, E. L., \& Neufeldt, S. A. (1995). Supervision: Its contribution to treatment efficacy. Journul of Consulting and Clinical Psychology, $63,207-213$.

Ilardi, S. S., \& Craighead, W. E. (1994). The role of nonspecific factors in cognitive-behavioral therapy for depression. Clinical Psychology: Science and Practice, $1,138-156$.

Jacobson, N. S., Dobson, K. S., Truax, P. A., Addis, M. E., Koerner, K., Gollan, J. K., Gortner, E., \& Prince, S. E. (1996). A component analysis of cognitive-behavioral treatment for depression. Journal of Consulting and Clinical Psychology, 64, 295-304.

Jacobson, N. S., \& Hollon, S. D. (1996). Cognitive-behavior therapy versus pharmacotherapy: Now that the Jury's returned its verdict, its time to present the rest of the evidence. Journal of Consulting and Clinical Psychology; 64, 74-80.

Jacobson, N. S., \& Truax, P. (1991). Clinical significance: A statistical approach to defining meaningful change in psychotherapy research. Joumal of Consulting and Clinical Psychology, 59, 12-19.

Kendall, P. C., \& Norton-Ford, J. D. (1982). Therapy outcome research methods. In P. C. Kendall \& J. N. Butcher (Eds.), Handbook of research methods in clinical psychology (pp. 429-460). New York: Wiley.

Klerman, G. L., \& Weissman, M. M. (Eds.). (1993). New applications of interpersonal psychotherapy. Washington, DC: American Psychiatric Press.

Klerman, G. L., Weissman, M. M., Rounsaville, B. J., \& Chevron, E. S. (1984). Interpersonal psychotherapy of depression. New York: Basic Books.

Krupnick, J. L., Sotsky, S. M., Simmens, S., Moyer, J., Elkin, I., Watkins, J., \& Pilkonis, P. A. (1996). The role of the therapeutic alliance in psychotherapy and pharmacotherapy outcome: Findings in the Na- tional Institute of Mental Health Treatment of Depression Collaborative Research Program. Journal of Consulting and Clinical Psychology. 64, 532-539.

Levenson, H., \& Strupp, H. H. (1996, August). Training in brief dynamic psychotherapy. The future of psychotherapy training: Some selected theory-driven perspectives. Symposium presented at the 104th Annual Convention of the American Psychological Association, Toronto, Ontario, Canada.

Lewinsohn, P. M., Antonuccio, D. O., Steinmetz, J. L., \& Teri, L. (1984). The coping with depression course. Eugene, OR: Castalia.

Linehan, M. M. (1993). Cognitive-behavioral treatment of borderline personality disorder. New York: Guilford Press.

Luborsky, L. (1990). Theory and technique in dynamic psychotherapyCurative factors and training therapists to maximize them. Psychotherapy and Psychosomatics, 53, 50-57.

Matarazzo, R. G., \& Patterson, D. R. (1986). Methods of teaching therapeutic skill. In S. L. Garfield \& A. E. Bergin (Eds.), Handbook of psychotherapy and behavior change (3rd ed., pp. 821-843). New York: Wiley.

Miller, W. R., \& Rollnick, S. (1991). Motivational interviewing: Preparing people to change addictive behavior. New York: Guilford Press.

Moras, K. (1993). The use of treatment manuals to train psychotherapists: Observations and recommendations. Psychotherapy, 30, 581586.

Prochaska, J. O., DiClemente, C. C., \& Norcross, J. C. (1992). In search of how people change: Applications to addictive behaviors. American Psychologist, 47, 1102-1114.

Rosin, S. A., \& Knudson, R. M. (1986). Perceived influence of life experiences on clinical psychologists' selection and development of theoretical orientation. Psychotherapy, 23, 357-362.

Rounsaville, B. J., Chevron, E. S., Weissman, M. M., Prusoff, B. A., \& Frank, E. (1986). Training therapists to perform interpersonal psychotherapy in clinical trials. Comprehensive Psychiatry, 27, 364-371.

Stein, D. M., \& Lambert, M. J. (1995). Graduate training in psychotherapy: Are therapy outcomes enhanced? Journal of Consulting and Clinical Psychology, 63, 182-196.

Strupp, H. H., \& Binder, J. L. (1984). Psychotherapy in a new key. New York: Basic Books.

Task Force on Promotion and Dissemination of Psychological Procedures. (1995). Training in and dissemination of empirically-validated psychological treatments: Report and recommendations. Clinical Psychologist, 48, 3-23.

Tingey, R. C., Lambert, M. J., Burlingame, G. M., \& Hansen, N. B. (1996). Assessing clinical significance: Proposed extensions to method. Psychotherapy Research, 6, 109-123.

VandeCreek, L., Knapp, S., \& Brace, K. (1990). Mandatory continuing education for licensed psychologists: Its rationale and current implications. Professional Psychology: Research and Practice, 21, 135-140.

Watson, D., \& Clark, L. A. (Eds.). (1994). Personality and psychopathology [Special issue]. Journal of Abnormal Psychology, 103 (1).

Wilson, T. G. (1996). Manual-based treatments: The clinical application of research findings. Behaviour Research and Therapy, 34, 295-314.

Zarin, D. A., \& Earls, F. (1993). Diagnostic decision making in psychiatry. American Journal of Psychiatry, 150, 197-206.

Received February 4, 1997

Revision received June 5, 1997

Accepted June 9, 1997 